\title{
Electrospinning of Heparin Encapsulated P(LLA-CL) Core/Shell Nanofibers
}

\author{
Feng Chen ${ }^{1 *}$, Peng Huang ${ }^{2}$, Xiu-Mei $\mathrm{Mo}^{3 *}$ \\ ${ }^{1}$ State Key Laboratory of High Performance Ceramics and Superfine Microstructure, Shanghai Institute of Ceramics, Chinese Academy \\ of Sciences, Shanghai 200050, China ${ }^{2}$ Institute of Micro-Nano Science and Technology, Shanghai Jiao Tong University, \\ Shanghai200240, China ${ }^{3}$ College of Chemistry, Chemical engineering and Biotechnology, Donghua University, Shanghai, 201620, \\ China
}

*Corresponding authors. Email: Fchen@mail.sic.ac.cn, xmm@dhu.edu.cn

\begin{abstract}
Coaxial electrospinning was developed for simultaneously electrospinning two different polymer solutions into core/shell nanofibers, or encapsulated bioactive molecular and drugs into polymer nanofibers for controlled release. In this study, heparin encapsulated poly(L-lactic acid-co- $\varepsilon$-caprolactone) $[\mathrm{P}(\mathrm{LLA}-\mathrm{CL})]$ core/shell nanofibers were fabricated in water/2, 2, 2-Trifluoroethanol mixed solvent through coaxial electrospinning. TEM images clearly proved the core/shell structure of nanofibers when the proportion of feeding rates of inner and outer solutions was at 1:3. The morphology of these nanofibers were investigated and discussed from SEM micrographs, and the diameters showed a normal distribution. Furthermore, the fabrics of heparin encapsulated P(LLA-CL) core/shell nanofibers showed a strong inhibit ability on proliferation of fibroblast in cell viability test in vitro.
\end{abstract}

Keywords: Nanofibers; Heparin; Electrospinning; P(LLA-CL)

Citation: F. Chen et al, Electrospinning of Heparin Encapsulated P(LLA-CL) Core/Shell Nanofibers, Nano Biomed Eng. 2010, 2(1), 56-60. DOI: 10.5101/nbe.v2i1.p56-60.

\section{Introduction}

Electrospinning has been recognized as an efficient technique for fabricating polymer nanofibers which could mimic native fibers structure of extra cellular matrix, and be widely used in biomedical area [1-3]. Electrospun nanofibers have received much attention because of their potential applications for biomedical devices, tissue engineering scaffolds, and drug delivery carriers [4]. The development in electrospun fibers has shown that the electrospinning is a promising way for future advanced composite systems [5]. Recently, a spinneret composed of two coaxial capillaries was developed for simultaneously electro- spinning two different polymer solutions into core/shell structured nanofibers [6-7]. Under this technique, various nanofibers were prepared, such as surface-modified nanofibers [8], continuous hollow nanofibers [9], and other functional nanofibers [10]. In addition, it is a powerful method to encapsulated bioactive molecular and drugs into biodegradable polymer [11-14].
Heparin has long been known to inhibit the proliferation of many kinds of cells, such as mesangial cell [15], fibroblast [16] and the vascular smooth muscle cell (VSMC) [17-18]. In Luong-Van's report, heparin was blended into poly(e-caprolactone) (PCL), and electrospun into nanofibers which showed effective ability in preventing the proliferation of smooth muscle cells [19]. Poly(L-lactide-co-e-caprolactone) [P(LLACL)] is a block copolymer of PLLA and PCL, and has been investigated as biomaterials used for surgery and drug delivery system because of good biocompatibility and biodegradability [20].

In this study, heparin contained P(LLA-CL) nanofibers with core/shell structure were obtained using coaxial electrospinning first time. The effect of feeding rate on structure of nanofibers was investigated with TEM. The morphology of nanofibers and the inhibition effect on proliferation of fibroblast were also studied. 
and $0.6 \mathrm{~mL} / \mathrm{h}$ (Table 1$)$. The total feeding ratio was at $1.2 \mathrm{~mL} / \mathrm{h}$. Therefore, the proportions of core and shell solution were $1: 3,1: 2$ and $1: 1$. Pure P(LLA-CL) nanofibers was also spun out at a concentration of $6 \%$ as a control.

The structure and morphology of the nanofibers were investigated by TEM (HITACHIH-800, Japan) and SEM (JSM-5600, JEOL, Japan). As for cell viability test, coverslips (14 $\mathrm{mm}$ in diameter) were used to collect the nanofibers for mat-like fabrics. Then, the fabrics were fixed in 24-well plates with stainless rings and sterilized with $75 \%$ alcohol solution. Fibroblast cells were maintained in 1640 medium supplemented with $10 \%$ fetal bovine serum (FBS), penicillin (100 units $/ \mathrm{mL})$ and streptomycin $(100 \mu \mathrm{g} / \mathrm{mL})$ at $37{ }^{\circ} \mathrm{C}$ in a $5 \% \mathrm{CO}_{2}$ humidified atmosphere. Confluent cells were subcultured every $3 \mathrm{~d}$ using standard procedure. For cell viability studies, cells were seeded at a density of $3.0 \times 10^{4}$ cells $/ \mathrm{cm}^{2}$ onto the fabrics and tissue culture plates (TCPs) in 24 well plates. At 24, 48, and $72 \mathrm{~h}$, the viability of cells were quantified by MTT (sigma, USA) and Enzyme-labeled Instrument (MK3, Thermo, USA). Data were representative of three independent experiments and all data points were plotted as means \pm standard deviation $(\mathrm{SD})(\mathrm{n}=3)$. Statistical analysis was performed using Origin 7.5 (Origin Lab Inc., USA). Samples that passed normality and equal variance tests were evaluated using a one-way analysis of variance (ANOVA). The priori alpha value was set at 0.05 with significance defined as $\mathrm{p} \leq 0.05$.

\section{Results and discussion}

As shown in Figure 2, the TEM image (Figure 2A) clearly proved the core/shell structure compared with P(LLA-CL) nanofiber (Figure 2D). The diameter of the core was about $90 \mathrm{~nm}$, while the diameter of the core/shell nanofibers was about $470 \mathrm{~nm}$. In the process of electrospinning, the stable compound jet and smooth nanofibers could form when the flow rate of the inner liquid were at 0.3 and $0.4 \mathrm{~mL} / \mathrm{h}$. The diameter of the core increased with the flow rate of the inner liquid increased from 0.3 to $0.4 \mathrm{~mL} / \mathrm{h}$. however, when the flow rate of inner liquid was up to $0.6 \mathrm{~mL} / \mathrm{h}$, a string of beads were observed in the nanofiber (Figure 2C).

The diameter of core layer increased with increasing feeding rate of inner solution. However, the overloading of inner solution could lead the presence of beads. The probably reason was the different properties of shell and core solutions. The water and TFE (boiling point $73.6{ }^{\circ} \mathrm{C}$ ) had different volatility. Therefore, the increased water content could prohibit expeditiously vaporizing of mixed solvent from nanofibers. The inner part in nanofibers could not be pulled down eventually 


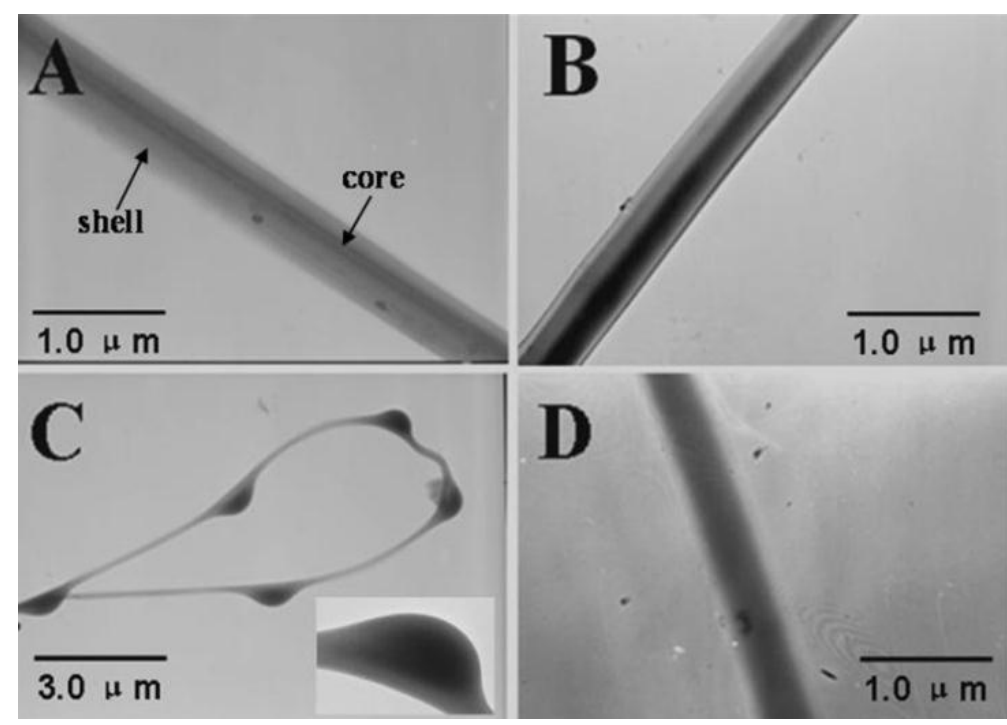

Figure 2. TEM images of core/shell (A-C) and pure P(LLA-CL) (D) nanofibers. The proportions of feeding ratios between inner solution and outer solution were (A) 1:3, (B) 1:2 and (C) 1:1.
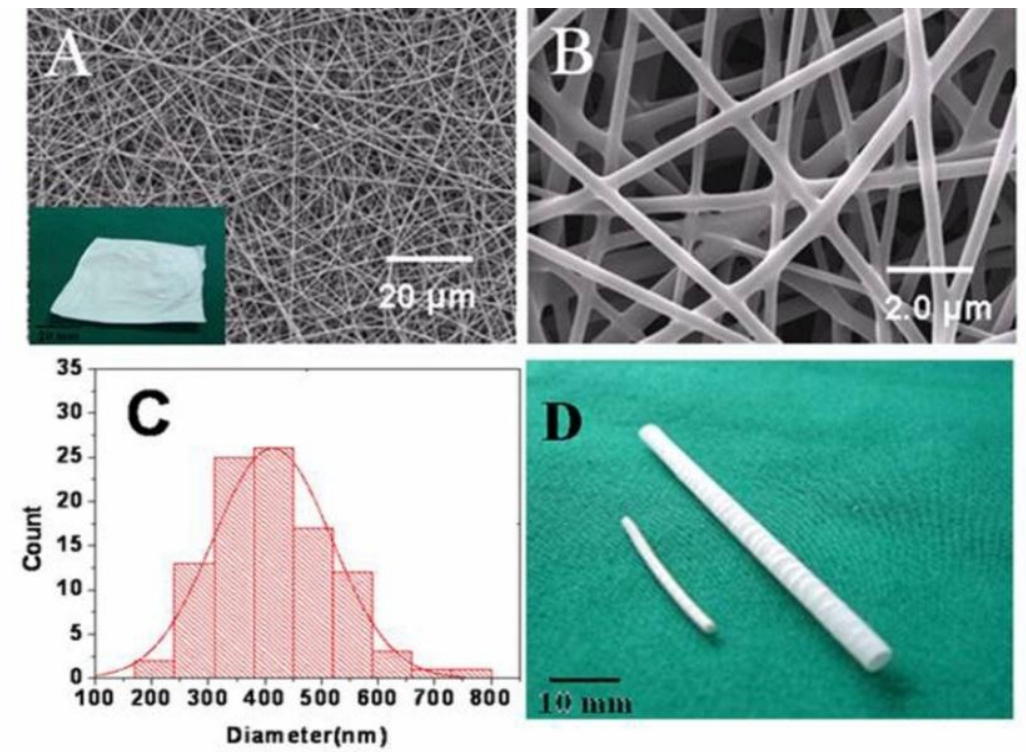

Figure 3. SEM images (A, B), diameters distribution (C) and tubular fabrics (D) of core/shell nanofibers.

compared with the out layer, and then the beads formed in the nanofibers.

The fine core/shell nanofibers were easily obtained through coaxial electrospinning at a proportion of $1: 3$ (Figure 3). The diameters of these nanofibers were measured based on the SEM micrographs by using an image visualization software Image $\mathrm{J}$ developed by Upper Austria University of Applied Sciences. The diameters of 100 nanofibers showed a normal distribution, and the average diameter was $413 \mathrm{~nm}$ (Figure 3C). Furthermore, the core/shell nanofibers were also easily used to form 3D structures by changing collector. The tubular scaffolds were collected on rotaring mandrels with diameters at 1.5 and $4 \mathrm{~mm}$ in this study (Figure 3D).
Fabroblast cell viability on heparin-contained nanofibers and pure P(LLA-CL) nanofibers were tested by MTT method (Figure 4). Initially, cell growth gradually till culturing time of $48 \mathrm{~h}$, but after that cell growth faster on pure P(LLA-CL) nanofibers than on heparin contained nanofibers. MTT absorption was significantly different on pure P(LLA-CL) and heparincontained nanofibers when fibroblast cell cultured for $72 \mathrm{~h}$. Proliferation of fibroblasts is a serious problem in surgical wound healing. Based on the location of the injury, the growth of fibroblasts can lead to different problems such as scar tissue formation and premature wound closure. This kind of fabric constructed with heparin incorporated P(LLA-CL) core/shell nanofibers may contribute to a new treatment for these situation caused by exceeding proliferation of fibroblast. 


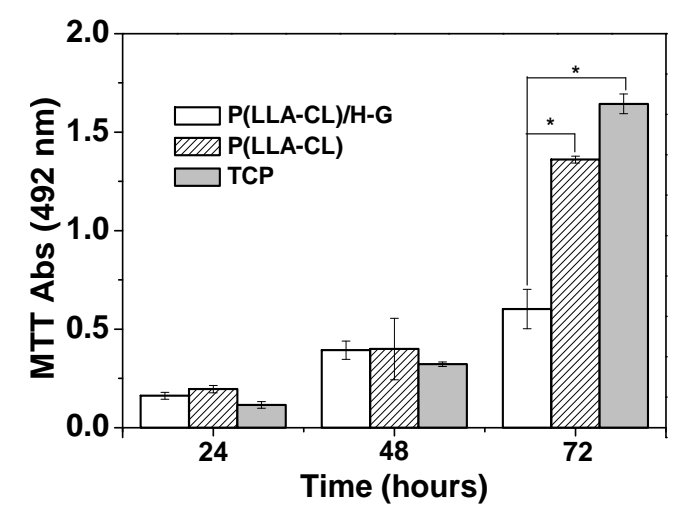

Figure 4. Inhibition effect of heparin contained core/shell nanofibers on proliferation of fibroblasts.

\section{Conclusion}

Heparin incorporated P(LLA-CL) nanofibers were obtained through coaxial electrospinning in water/TFE mixed solvent. When the proportion of feeding rate in process of fabrication between inner solution and outer solution were 1:3, TEM investigations clearly proved the core/shell nanofiber of nanofibers. The diameters of 100 nanofibers showed a normal distribution, and the average diameter was $\sim 413 \mathrm{~nm}$. These nanofibers were easily used to form mats or tubular structures. The fabrics of heparin incorporated P(LLA-CL) core/shell nanofibers showed strong ability of inhibit effect on proliferation of fibroblast.

\section{Acknowledgements}

This research was supported by the National HighTech Research and Development Programme of China (863 Program, 2008AA03Z305), National Nature Science Foundation of China (30570503), Science and Technology Commission of Shanghai Municipality Program (08520704600, and 0852nm03400).

\section{References}

1. Liao S, Li B, Ma ZW, Wei H, Chan C, Ramakrishna S. Biomimetic electrospun nanofibers for tissue renegeration. Biomed Mater 2006; 1: R45-R53. doi:10.1088/17486041/1/3/R01 doi:10.1088/1748-6041/1/3/R01

2. Yoshimoto H, Shin YM, Terai H, Vacanti JP. A biodegradable nanofiber scaffold by electrospinning and its potential for bone tissue engineering. Biomaterials 2003; 24: 2077-2082. doi:10.1016/S0142-9612(02)00635-X

3. $\mathrm{Xu} \mathrm{CY}$, Inai $\mathrm{R}$, Kotaki $\mathrm{M}$, Ramakrishna $\mathrm{S}$. Electrospun nanofiber fabrication as synthetic extra cellular matrix and its potential for vascular tissue engineering. Tissue Eng 2004; 10: 1160-1168.

4. Yoo HS, Kim TG, Park TG. Surface-functionalized electrospun nanofibers for tissue engineering and drug delivery. Adv Drug Deliv Rev 2009; 61: 1033-1042. doi:10.1016/j.addr.2009.07.007

5. Teo WE, Ramakrishna S. Electrospun nanofibers as a platform for multifunctional, hierarchically organized nanocomposite. Compos Sci Technol 2009; 69: 1804-1817. doi:10.1016/i.compscitech.2009.04.015

6. Sun ZC, Zussman E, Yarin AL, Wendorff JH, Greiner A. Compound core-shell polymer nanofibers by coelectrospinning. Adv Mater 2003; 15: 1929-1932. doi:10.1 002/adma.200305136

7. Zhang YZ, Huang ZM, Xu XJ, Lim CT, Ramakrishna S. Preparation of core-shell structured PCL-r-gelatin bicomponent nanofibers by coaxial electrospinning. Chem Mater 2004; 16: 3406-3409. doi:10.1021/cm049580f

8. Zhang YZ, Venugopal J, Huang ZM, Lim CT, Ramakrishna S. Characterization of the surface biocompatibility of the electrospun pcl-collagen nanofibers using fibroblasts. Biomacromolecules 2005; 6: 2583-2589. doi:10.1021/bm0 $\underline{50314 \mathrm{k}}$

9. Li D, Xia YN. Direct fabrication of composite and ceramic hollow nanofibers by electrospinning. Nano Lett 2004; 4: 933-938. doi:10.1021/n1049590f

10. Kwak G, Lee GH, Shim SH, Yoon KB. Fabrication of light-guiding core/sheath fibers by coaxial electrospinning. Macromol Rapid Commun 2008; 29: 815-820. doi:10.1002/marc.200800065

11. Jiang H, Hu Y, Li Y, Zhao P, Zhu K, Chen W. A facile technique to prepare biodegradable coaxial electrospun nanofibers for controlled release of bioactive agents. $J$ Control Release 2005; 108: 237-243. doi:10.1016/j.j conrel.2005.08.006

12. Zhang YZ, Wang X, Feng Y, Li J, Lim CT, Ramakrishna S. Coaxial electrospinning of (fluorescein isothiocyanateconjugated bovine serum albumin)-encapsulated poly(caprolactone) nanofibers for sustained release. Biomacromolecules 2006; 7: 1049-1057. doi:10.1021/bm050743i

13. Jiang HL, Hu YQ, Zhao PC, Li Y, Zhu KJ. Modulation of protein release from biodegradable core-shell structured fibers prepared by coaxial electrospinning. J Biomed Mater Res Part B 2006; 79: 50-57.

14. He CL, Huang ZM, Han XJ, Liu L, Zhang HS, Chen LS. Coaxial electrospun poly(l-lactic acid) ultrafine fibers for sustained drug delivery. J Macromol Sci B 2006; 45: 515524. doi:10.1080/00222340600769832

15. Floege J, Eng E, Young BA, Couser WG, Johnson RJ. Heparin suppresses mesangial cell proliferation and matrix expansion in experimental mesangioproliferative glomerulonephritis. Kidney Int 1993; 43: 369-380. doi:10.1 $\underline{038 / \mathrm{ki} .1993 .55}$

16. Del Vecchio PJ, Bizios R, Holleran LA, Judge TK, Pinto GL. Inhibition of human scleral fibroblast proliferation with heparin. Invest Ophthalmol Vis Sci 1988; 29: 1272-1276.

17. Clowes AW, Karnowsky MJ. Suppression by heparin of smooth muscle cell-proliferation in injured arteries. Nature 1977; 265: 625-626. doi:10.1038/265625a0 
18. Hoover RL, Rosenberg R, Haering W, Karnovsky MJ. Inhibition of rat arterial smooth muscle cell proliferation by heparin II. In vitro studies. Circ Res 1980; 47: 578-583.

19. Luong-Van E, Grondahl L, Chua KN, Leong KW, Nurcombe V, Cool SM. Controlled release of heparin from poly(-caprolactone) electrospun fibers. Biomaterials 2006; 27: 2042-2050. doi:10.1016/j.biomaterials.2005.10.028

20. Ikada Y. Tissue engineering: Fundamentals and applications (1st Edition), Academic Press, 2006.

Received 20 February, 2010; accepted 3 March, 2010; published online 5 March, 2010.

Copyright: (c) 2010 F. Chen et al. This is an open-access article distributed under the terms of the Creative Commons Attribution License, which permits unrestricted use, distribution, and reproduction in any medium, provided the original author and source are credited. 